\title{
Sequential path analysis of some yield and quality components in sugar beet grown in normal and drought conditions
}

\author{
Mehdi Baradaran Firouzabadi, Naser Farrokhi, Mahdieh Parsaeyan \\ Department of Agronomy and Plant Breeding, Shahrood University of Technology, Iran
}

\begin{abstract}
Through biometrical analyses of yield and its components selection indices can be generated and be used in future breeding programs. Sugar yield components were considered as the first order variables (FOV) in previous path analyses studies, while white sugar yield (WSY) and its related traits were the FOV here. Three lines of sugar beet (7219-P.69, BP-Karaj, 7112) were evaluated in drought and nondrought conditions. Two sequential path models were used for analysis of associations among WSY and its related traits by arraying the independent variables in first-, second-, and third-order paths on the basis of their maximum direct effects and minimal collinearity. Four first-order variables, namely root diameter, sugar yield, molasses content and sugar content, revealed highest direct effects on WSY under normal condition, while root length, $\alpha$-amino-N, root yield, crown dry weight, water use efficiency and $\mathrm{Na}^{+}$were found to fit as second-order variables. Three first-order variables, namely sugar content, sugar yield and molasses content, revealed highest direct effects on white sugar yield under drought-stress condition. In this case, sugar yield had the highest direct effect on WSY. In general, the sequential path analysis efficiently demonstrated the effects of predictor variables.
\end{abstract}

\section{Introduction}

The yield components in sugar beet (Beta vulgaris L.) consist of biomass-, root, and sugar-yield of which the white sugar yield is concerned as the most important component (Mohammadi and Assad, 1997). Therefore, understanding the sugar yield interrelationships

Correspondence: Dr. Naser Farrokhi, Faculty of Agriculture, Shahrood University of Technology, P.0. Box 316, Shahrood, Iran.

E-mail: nfarrokh@nigeb.ac.ir

Key words: correlation, drought, sequential path model, stepwise regression, sugar beet.

Received for publication: 6 June 2011.

Accepted for publication: 3 December 2011.

(C) Copyright M. Baradaran Firouzabadi et al., 2011

Licensee PAGEPress, Italy

Italian Journal of Agronomy 2011; 6:e39

doi:10.4081/ija.2011.e39

This work is licensed under a Creative Commons Attribution NonCommercial 3.0 License (CC BY-NC 3.0). with other agronomic traits may lead in determination of selection indices for higher white sugar yield.

Sugar content, and both chemical and physical states of beet roots, known as beet quality, greatly affect sugar and its by-product yield. Beet quality is defined by the optimum condition that provides the higher sugar content next to the lower amounts of non-sugar compounds, mainly $\alpha$-amino-N, glycine betaine, proline, sodium and potassium (Gzik, 1996). These impurities inhibit the crystallization of sucrose and increase the molasses production rate (Dunham and Clark, 1992; Harvey and Dutton, 1993). The rate of these non-sugar compounds usually increases upon drought stress, lowering the sugar beet quality (Clarke et al., 1993).

Although correlation studies reveal the genetic gain of a trait upon selection, it would not be definitive in cases where numerous independent variables are involved in controlling the dependent trait (Agrama, 1996; Board et al., 1997). To resolve this, path analysis would be a useful technique in breaking down the direct correlations of independent variables into their direct and indirect effects and establishing their relations to the dependent trait (Williams et al., 1990). In path analysis, the variables that are most effective on dependent variable are being considered as the first-order predictors of response variable that is mainly yield in agricultural studies (Maity and Chattarzee, 1977; Gunel et al., 1991; Gopal et al., 1994; Yildirim et al., 1997; Bhagowati and Saikia, 2003; Tuncturk and Çiftçi, 2005). However in places where the independent variables have correlation with each other, multicollinearity (combining effects of different correlated variables) obscures the interpretation of results (Milligan et al., 1990; Hiar et al., 1995). Samonte et al. (1998) developed a sequential path analysis and used it to determine the interrelationships of rice yield and its components considering minimizing the multicollinearity. Thus, sequential path analysis may improve the reliability of results by placing the predictor variables in different orders of relation to the response variable (usually up to three orders) and eventually eliminating the multicollinearity. Previous studies emphasize on the trustworthiness of sequential path analysis in contrast to single-step path analysis (Agrama, 1996; Mohammadi et al., 2003; Asghari-Zakaria et al., 2007).

Here, correlation and two sequential path analyses (SPA) were used to reveal the predictor traits on white sugar yield (WSY) for sugar beet breeding grown under normal and drought-stressed conditions.

\section{Materials and Methods}

\section{Field trial}

The experiment was performed in Karaj, Iran in 2002. The soil was calcic brown silty clay $(\mathrm{pH}=7.6, \mathrm{EC}=0.6)$. The average rainfall for a period of 35 years was $243 \mathrm{~mm}$ occurring mostly during late autumn till early spring providing a xerothermo Mediterranean climate.

The experiment occupied a surface of $1500 \mathrm{~m}^{2}$ with 54 plots. Each 
plot contained 6 lines (7 m in length) with $50 \mathrm{~cm}$ and $20 \mathrm{~cm}$ inter-row and intra-row, respectively. Experimental design was a split block-like (Hanks et al., 1980) with Line-Source sprinkler irrigation system (three treatments) and three sugar beet lines in three replicates. According to Hanks et al. $(1976 ; 1980)$ irrigation treatments were not randomized (Figure 1).

The Line-Source divided the field into two equal parts. Surrounding rows of the Line-Source were 18; the first six-rows were in normal (receiving $1272 \mathrm{~mm}$ ), the middle six-rows in mild-stress (receiving $1141 \mathrm{~mm}$ ), and the last six-rows in severe-stress (receiving $739 \mathrm{~mm}$ ) conditions (Figure 1). The cultivars were tolerant (7219-P.69), semitolerant (Karaj-BP) and sensitive (7112) to drought condition. Following the complete establishment of plants, irrigation system was set and irrigation treatments were applied.

The soil leaching rate was measured at depths of $0-100 \mathrm{~cm}$ by the Time Domain Reflectometry (TDR, PALTIN International Inc., Maryland, USA). Delivered water volume per plot was measured by planted measuring containers within the center of each plot at $50 \mathrm{~cm}$ height.

\section{Sampling and data collection}

Destructive plant samples were collected during growth period at 170 and 210 days after sowing (DAF). The following traits were measured at $170 \mathrm{DAF}$; leaf dry weight (LDW), root dry weight (RDW), petiole dry weight (PDW), crown dry weight (CDW), total dry weight (TDW), leaf area index (LAI), root diameter (RD), root length (RL), water used (WU), and water use efficiency (WUE). Root yield (RY) and qualitative factors including potassium, sodium, and $\alpha$-amino- $\mathrm{N}$ were measured at 210 DAF. After pulp preparation with VENEMA Line (KHBC Ltd., Poland), all the qualitative factors were analyzed with Betalyser (model OR-KERNCHEN). Betalyser is a software applet for automated routine analysis of sugar content and beet impurities including $\mathrm{Na}+\mathrm{K}+$ and $\alpha$-amino-N. The instrument measures potassium and sodium via its flame photometer, $\alpha$-amino- $\mathrm{N}$ by double beam filter photometry using the blue number method (Stanek and Pavlas, 1934; Sheikh-Aleslami, 1997) and sugar content (SC) through its polarimeter. Molasses content (MC) was calculated with the following formula:

$$
\mathrm{MC}=0.343(\mathrm{~K}+\mathrm{Na})+0.094(\alpha-\operatorname{amino}-\mathrm{N})-
$$$$
0.31 \text { (Reinefield et al., 1974) }
$$

Sugar yield (SY), and white sugar yield (WSY) were calculated after Reinefield et al. (1974) and according to the following formulas:

$$
\begin{gathered}
\mathrm{WSC}=\mathrm{SC}-\mathrm{MC} \\
\mathrm{WSY}=\mathrm{RY} * \mathrm{WSC} \\
\mathrm{SY}=\mathrm{RY} * \mathrm{SC}
\end{gathered}
$$

Alkaline level content (ALC) was calculated according to SheikhAleslami (1997) using the following formulae:

$$
\mathrm{ALC}=(\mathrm{K}+\mathrm{Na}) / \alpha \text {-amino- } \mathrm{N}
$$

\section{Statistical analyses}

Normality test of the data was performed with SPSS. The data demonstrated to be normal. Simple correlations were calculated and stepwise regression was followed to determine interrelationship between independent and dependent variables and further to reveal the first-, second-, and third-paths of predictor variables.

The independent variables were grouped according to their contribution in yield considering minimal multicollinearity effect. Sequential path analysis was followed according to Samonte et al. (1998) to reveal the cause-effect relationship. The first order independent variables were the traits with highest regression coefficients in the stepwise regression. Consecutively, these independent traits were considered as dependent variables to the remaining traits and second stepwise regressions were performed to reveal the second order independent traits. These steps were followed to reveal the third order independent traits.
In order to compare single-step path analyses with sequential path analyses variance inflation factors (VIF) and tolerance values (TV) were measured via SPSS 11.5 (Williams et al., 1990; Hiar et al., 1995). The variability of selected independent variables can be explained by $T V=1-R_{i}{ }^{2}\left(R_{i}{ }^{2}\right.$ is the coefficient of determination for the prediction of variable I by the predictor variables). $0 n$ the other hand, $\mathrm{VIF}(\mathrm{VIF}=1 /(1-$ $\mathrm{R}_{\mathrm{i}}{ }^{2}$ )) demonstrates the extent of the effects of other independent variables on the variance of the selected independent variable. A high degree of multicollinearity can be explained by values greater than 10 for VIF and values smaller than 0.1 for TV (Wang et al., 1999; Mohammadi et al., 2003).

\section{Results}

Here, for the sake of simplicity the mid and sever stress treatments were combined and the average trait measurements were considered as the drought condition.

\section{Simple correlation analyses}

Simple correlation coefficients are presented in Tables 1 and 2 for both normal and drought-stressed conditions. In normal condition, a positive correlation was observed between WSY and SC (0.8) and negative significant correlations were observed with PDW and sodium. However, a non-significant negative correlation was seen with WSY (Table 1).

In stressed condition, SY and RY had the highest positive correlation with WSY, 0.95 and 0.76 respectively. RD also had a significant positive correlation with WSY (Table 2). WUE in stressed condition had lower effect on WSY compared to the normal condition (0.14 against 0.90$)$.

\section{Stepwise regression and sequential path analysis in normal condition}

White sugar yield was considered as the dependent variable against the rest of the traits and stepwise regression was performed (Table 1 and Figure 1). Root diameter, sugar yield, molasses content and sugar content were kept in the model $\left(\mathrm{R}^{2}=0.98\right)$ and path analysis was followed (Table 1 and Figure 1). SY had the highest direct effect on WSY, while RD and MC had minor direct effect. Although SC had a high and positive correlation with WSY, its direct effect was much lower compared to SY (019). Meanwhile the SC's indirect positive effect via SY was high, suggesting its contribution to WSY.

In the second order, the above traits (RD, SY, MC and SC) were considered as dependent traits and stepwise regression was performed for each separately (Table 1 and Figure 1). Similarly, traits with the highest interrelationships with the above traits remained in the model. For $\mathrm{RD}$, only root length remained in the model with the same correlation coefficient as RD (0.67, Table 1 and Figure 1). Water use efficiency, RY, sodium, and crown dry weight were present in the model for SY (Table 1). The first three traits had the highest direct effect on $S Y(0.47,0.46$, and -0.44 , respectively). Although CDW had a negative correlation with SY $(-0.45$, Table 1$)$, it had a positive direct effect on this trait $(0.18$, Figure 1). It appears the indirect negative effects through WUE and RY contributes to this negative correlation (Table 1). In case of MC, RY, sodium, potassium, $\alpha$-amino- $\mathrm{N}$ were the remaining traits in the model (Table 1 and Figure 1). The highest direct effects belonged to $\mathrm{Na}^{+}$and $\mathrm{K}^{+}(0.62$ and 0.8 , respectively). The indirect effects had minor values, suggesting that the major contribution of these traits were through their direct effects on MC. When SC was considered as dependent trait, the only trait appeared in the model was sodium content with a high negative effect (-0.88, Table 1 and Figure 1$)$.

In the third order, traits appeared in the second step as independent 
Table 1. Correlation coefficients between traits measured in three lines of sugar beet in normal condition. Correlation coefficients more than 0.32 and 0.43 are significant at the 0.05 and 0.01 probability levels, respectively.

\begin{tabular}{|c|c|c|c|c|c|c|c|c|c|c|c|c|c|c|c|c|c|c|c|c|c|}
\hline \multirow{2}{*}{ LDW } & LDW & RDW & PDW & CDW & TDW & LAI & SLW & LWR & LAR & RD & RL & $\mathbf{K}$ & $\mathrm{Na}$ & $\mathbf{N}$ & ALC & MC & WU & WUE & SC & SY & RY \\
\hline & & & & & & & & & & & & & & & & & & & & & \\
\hline RDW & -0.49 & & & & & & & & & & & & & & & & & & & & \\
\hline PDW & 0.87 & -0.77 & & & & & & & & & & & & & & & & & & & \\
\hline CDW & 0.87 & -0.46 & 0.67 & & & & & & & & & & & & & & & & & & \\
\hline TDW & -0.1 & 0.90 & -0.46 & -0.12 & & & & & & & & & & & & & & & & & \\
\hline LAI & 0.98 & -0.47 & 0.90 & 0.72 & -0.08 & & & & & & & & & & & & & & & & \\
\hline SLW & -0.82 & 0.34 & -0.81 & -0.58 & -0.01 & -0.8 & & & & & & & & & & & & & & & \\
\hline LWR & 0.79 & -0.86 & 0.87 & 0.52 & -0.64 & 0.75 & -0.60 & & & & & & & & & & & & & & \\
\hline LAR & 0.85 & -0.82 & 0.93 & 0.60 & -0.56 & 0.84 & -0.73 & 0.97 & & & & & & & & & & & & & \\
\hline RD & -0.43 & 0.33 & -0.30 & -0.42 & 0.18 & -0.3 & 0.15 & -0.4 & -0.41 & & & & & & & & & & & & \\
\hline RL & -0.28 & 0.19 & -0.22 & -0.21 & 0.1 & -0.3 & 0.11 & -0.3 & -0.29 & 0.67 & & & & & & & & & & & \\
\hline $\mathbf{K}$ & -0.50 & 0.39 & -0.49 & -0.43 & 0.21 & -0.5 & 0.41 & -0.4 & -0.48 & 0.47 & 0.35 & & & & & & & & & & \\
\hline $\mathrm{Na}$ & 0.41 & -0.51 & 0.57 & 0.65 & -0.32 & 0.48 & -0.45 & 0.42 & 0.52 & -0.06 & -0.06 & -0.08 & & & & & & & & & \\
\hline $\mathbf{N}$ & -0.21 & -0.20 & 0.04 & 0.01 & -0.28 & 0.12 & 0.06 & -0.1 & -0.03 & 0.12 & 0.24 & 0.09 & -0.02 & & & & & & & & \\
\hline ALC & 0.30 & 0.08 & 0.05 & 0.14 & 0.20 & 0.24 & -0.02 & 0.12 & 0.10 & -0.12 & -0.22 & -0.06 & 0.04 & -0.90 & & & & & & & \\
\hline MC & -0.19 & -0.03 & -0.03 & 0.05 & -0.07 & -0.1 & 0.06 & -0.1 & -0.07 & 0.36 & 0.28 & 0.77 & 0.54 & 0.24 & -0.18 & & & & & & \\
\hline WU & 0.62 & -0.30 & 0.61 & 0.24 & -0.08 & 0.62 & -0.56 & 0.48 & 0.52 & -0.21 & -0.14 & -0.56 & -0.05 & -0.09 & 0.12 & -0.50 & & & & & \\
\hline WUE & -0.69 & 0.52 & -0.78 & -0.52 & 0.26 & -0.7 & 0.73 & -0.6 & -0.70 & 0.14 & 0.30 & 0.43 & -0.55 & 0.19 & -0.18 & 0.03 & -0.65 & & & & \\
\hline SC & -0.36 & 0.49 & -0.57 & -0.50 & 0.33 & -0.4 & 0.47 & -0.4 & -0.51 & -0.02 & 0.14 & 0.03 & -0.88 & 0.06 & -0.01 & -0.51 & -0.17 & 0.66 & & & \\
\hline SY & -0.59 & 0.45 & -0.67 & -0.45 & 0.22 & -0.6 & 0.63 & -0.5 & -0.60 & 0.12 & 0.34 & 0.36 & -0.61 & 0.27 & -0.28 & -0.04 & -0.47 & 0.92 & 0.67 & & \\
\hline RY & -0.50 & 0.17 & $-0,42$ & -0.19 & -0.05 & -0.5 & 0.45 & -0.3 & -0.37 & 0.17 & 0.33 & 0.46 & $-0,07$ & 0.36 & -0.38 & 0.38 & -0.48 & 0.67 & 0.05 & 0.76 & \\
\hline WSY & -0.50 & 0.48 & -0.69 & -0.49 & 0.26 & -0.6 & 0.62 & -0.4 & -0.60 & 0.07 & 0.29 & 0.23 & -0.73 & 0.20 & -0.22 & -0.22 & -0.39 & 0.90 & 0.80 & 0.97 & 0.62 \\
\hline
\end{tabular}

WSY, white sugar yield; RY, root yield; SY, sugar yield; SC, sugar content; WUE, water use efficiency; WU, water use; MC, molasses content; ALC, alkaline level content; N, $\alpha$-amino $\mathrm{N}$; Na, sodium; K, potassium; RL, root length; RD, root diameter; LAR, leaf area ratio; LWR, leaf weight ratio; SLW, specific leaf weight; LAI, leaf area index; TDW, total dry weight; CDW, crown dry weight; PDW, petiole dry weight; RDW, root dry weight; LDW, leaf dry weight.

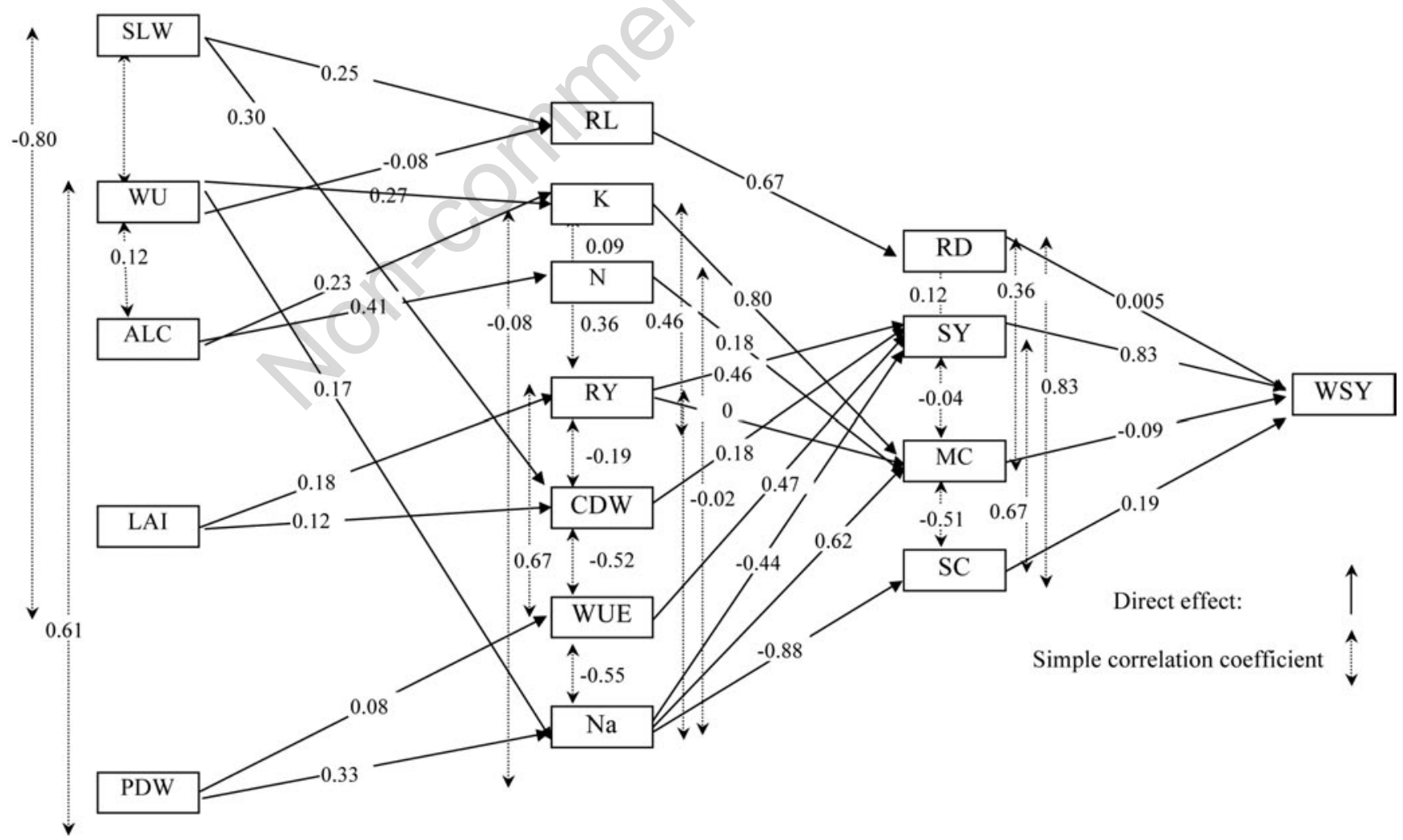

Figure 1. Sequential path model indicating interrelationships between white sugar yield and related traits in sugar beet in normal conditions. 
Table 2. Correlation coefficients between traits measured in three lines of sugar beet in drought stress condition. Correlation coefficients more than 0.35 and 0.47 are significant at the 0.05 and 0.01 probability levels, respectively.

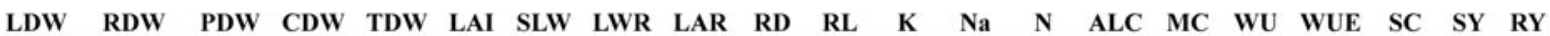

\begin{tabular}{|c|c|c|c|c|c|c|c|c|c|c|c|c|c|c|c|c|c|c|c|c|c|}
\hline LDW & & & & & & & & & & & & & & & & & & & & & \\
\hline RDW & -0.02 & & & & & & & & & & & & & & & & & & & & \\
\hline PDW & 0.28 & 0.38 & & & & & & & & & & & & & & & & & & & \\
\hline CDW & -0.29 & 0.25 & 0.49 & & & & & & & & & & & & & & & & & & \\
\hline TDW & 0.8 & 0.98 & 0.49 & 0.30 & & & & & & & & & & & & & & & & & \\
\hline LAI & 0.94 & 0.02 & 0.40 & -0.12 & 0.14 & & & & & & & & & & & & & & & & \\
\hline SLW & -0.04 & -0.09 & -0.49 & -0.42 & -0.15 & -0.34 & & & & & & & & & & & & & & & \\
\hline LWR & 0.70 & -0.58 & -0.12 & -0.59 & -0.52 & 0.57 & 0.13 & & & & & & & & & & & & & & \\
\hline LAR & 0.71 & -0.58 & 0.01 & -0.45 & -0.50 & 0.69 & -0.15 & 0.94 & & & & & & & & & & & & & \\
\hline RD & -0.04 & 0.26 & 0.08 & 0.09 & 0.25 & 0.07 & -0.18 & -0.31 & -0.20 & & & & & & & & & & & & \\
\hline RL & 0.02 & -0.26 & 0.34 & 0.24 & -0.21 & 0.14 & -0.41 & 0.07 & 0.22 & 0.07 & & & & & & & & & & & \\
\hline $\mathbf{K}$ & -0.59 & 0.51 & 0.05 & 0.33 & 0.44 & -0.54 & -0.01 & -0.67 & -0.68 & 0.24 & -0.11 & & & & & & & & & & \\
\hline $\mathrm{Na}$ & -0.22 & 0.38 & 0.17 & 0.36 & 0.37 & -0.11 & -0.30 & -0.32 & -0.25 & -0.06 & -0.03 & 0.53 & & & & & & & & & \\
\hline $\mathbf{N}$ & 0.23 & 0.16 & 0.24 & 0.02 & 0.19 & 0.35 & -0.42 & 0.06 & 0.18 & 0.37 & 0.59 & 0.01 & -0.15 & & & & & & & & \\
\hline ALC & -0.41 & 0.06 & -0.31 & 0.12 & -0.05 & -0.53 & 0.55 & -0.32 & -0.45 & -0.10 & -0.50 & 0.29 & 0.19 & -0.84 & & & & & & & \\
\hline MC & -0.51 & 0.54 & 0.11 & 0.38 & 0.49 & -0.42 & -0.15 & 0.63 & -0.60 & 0.22 & -0.03 & 0.96 & 0.71 & 0.07 & 0.19 & & & & & & \\
\hline $\mathbf{W U}$ & -0.24 & 0.31 & 0.52 & 0.60 & 0.34 & -0.02 & -0.59 & -0.55 & -0.36 & 0.59 & 0.18 & 0.24 & 0.10 & 0.26 & -0.16 & 0.26 & & & & & \\
\hline WUE & 0.14 & -0.43 & -0.58 & -0.47 & -0.46 & -0.04 & 0.65 & 0.37 & 0.22 & -0.02 & -0.23 & -0.11 & -0.51 & -0.15 & 0.28 & -0.26 & -0.51 & & & & \\
\hline SC & -0.02 & -0.29 & -0.27 & -0.24 & -0.31 & -0.21 & 0.57 & 0.17 & -0.03 & -0.04 & -0.05 & -0.27 & -0.82 & 0.09 & 0.02 & -0.46 & -0.14 & 0.61 & & & \\
\hline SY & -0.36 & 0.04 & 0.10 & 0.52 & 0.04 & -0.21 & -0.28 & -0.51 & -0.37 & 0.68 & 0.12 & 0.36 & -0.01 & 0.16 & 0.11 & 0.31 & 0.77 & 0.04 & 0.09 & & \\
\hline RY & -0.34 & 0.17 & 0.22 & 0.59 & -0.17 & -0.10 & -0.53 & -0.55 & -0.34 & 0.65 & 0.13 & 0.48 & 0.35 & 0.12 & 0.08 & 0.51 & 0.78 & -0.23 & -0.36 & 0.89 & \\
\hline WSY & -0.26 & -0.10 & 0.05 & 0.43 & -0.09 & -0.14 & -0.20 & -0.36 & -0.24 & 0.65 & 0.13 & 0.12 & -0.25 & 0.16 & 0.07 & 0.04 & 0.73 & 0.14 & 0.29 & 0.95 & 0.76 \\
\hline
\end{tabular}

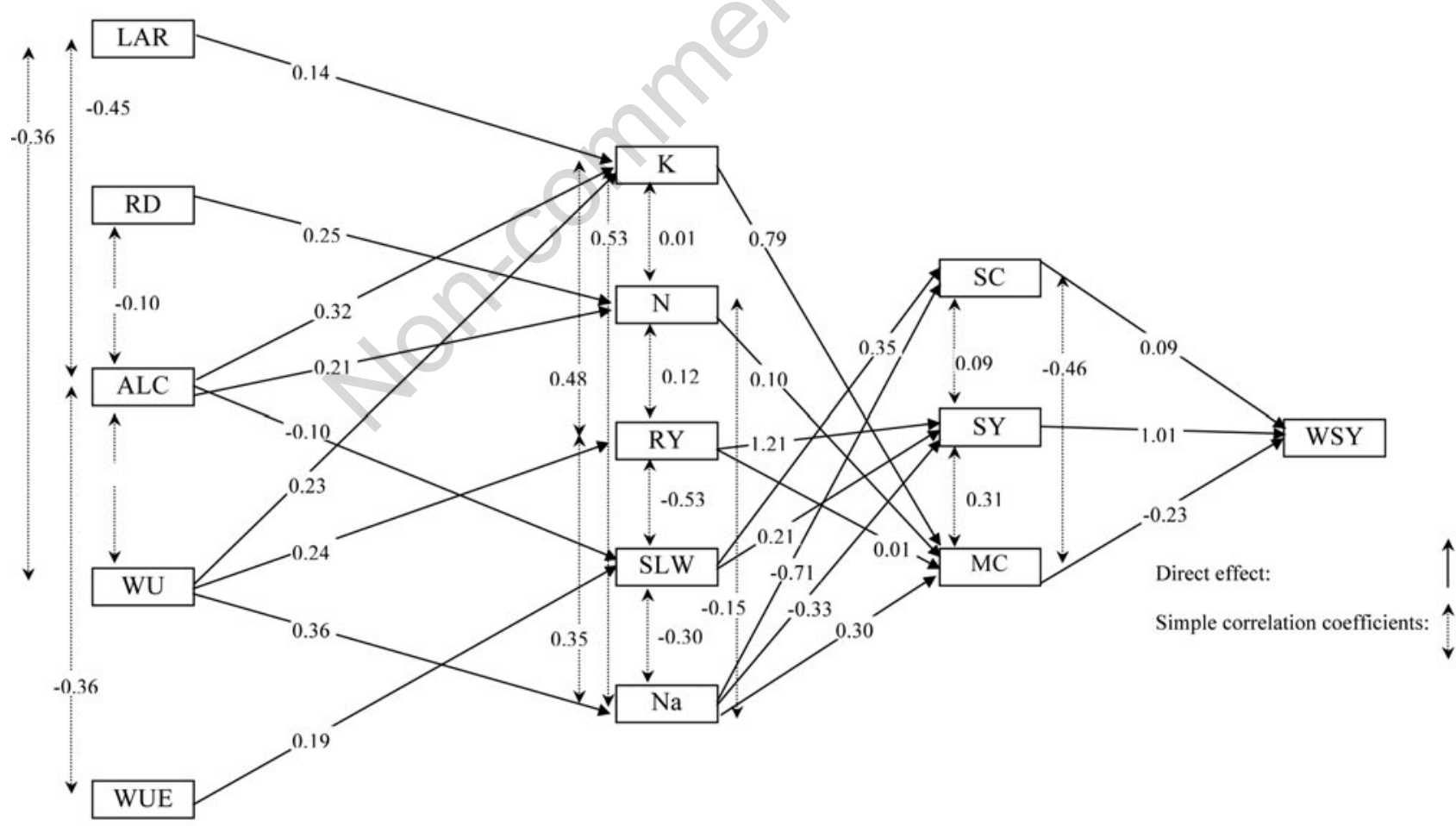

Figure 2. Sequential path model indicating interrelationships between white sugar yield and related traits in sugar beet in drought-stress conditions. 
variables (RL, K, Na, N, RY, CDW, WUE) were considered dependent variables. The interrelationships of these traits with the remaining traits were evaluated. Since the coefficients of determination $\left(R^{2}\right)$ of all models were very low, path analysis for the third order has not been discussed.

\section{Stepwise regression and sequential path analysis in drought-stressed condition}

Similar to normal condition, WSY was considered as the dependent variable and its interrelationship with other traits was evaluated. Three variables including sugar content, sugar yield and molasses content remained in the model following the first stepwise regression. Similar to the normal condition SY had the highest effect on WSY, while MC had a negative direct effect (Table 2 and Figure 2). In this model, RD was not kept and the direct effect of SC was minor.

For the second order path analysis, the above traits (SY, SC, and MC) were used as dependent variables in a stepwise regression and remaining traits were considered as independent traits. Root yield, specific leaf weight and sodium demonstrated a direct meaningful relation with sugar yield (Table 2 and Figure 2). Since the coefficient of determination was not as high as expected $(\mathrm{R} 2=0.63)$, it may suggest that other traits might be involved which either at this point were not included into the model or they have not been measured. RY had the highest direct effect on SY. SLW had a negative simple correlation with RY, but it demonstrated positive direct effect on SY. However, the indirect effect of SLW via RY was significant and negative. Moreover, the root sodium content also demonstrated a negative direct effect on SY. When $\mathrm{MC}$ was considered as the dependent variable, four independent variables including $\mathrm{K}^{+}, \mathrm{Na}^{+}$, $\mathrm{RY}$ and $\alpha$-amino- $\mathrm{N}$ were retained in the regression model. Among these variables, $\mathrm{K}+$ and $\mathrm{Na}+$ had the highest direct effect on MC with 0.79 and 0.3 , respectively (Figure 2). In addition to the direct effect of $\mathrm{Na}+$ on $\mathrm{MC}$, it demonstrated a considerable amount of indirect effect mainly via $\mathrm{K}+$. By considering the $\mathrm{SC}$ as the dependent variables, SLW and root $\mathrm{Na}+$ were the only traits that entered into the model (Figure 2). The coefficient of determination was low $\left(\mathrm{R}^{2}=0.57\right)$, suggesting probable presence of other traits affecting $\mathrm{SC}$ that were not measured in this experiment.

In the third order of stepwise regression where the independent variables of second step considered being the dependent variables, the coefficients of determination were low and similar to the normal condition the path analysis was not conducted.

\section{Comparative studies of single-step path analyses and sequential path analyses}

Tolerance values (TV) and variance inflation rates (VIF) were calculated for both single-step path analyses and sequential path analyses (Tables 3 and 4). The values demonstrated elimination of multicollinearity in the latter approach.

Table 3. Comparison of multicollinearity in sequential path model and conventional path analysis by tolerance value xand variance inflation factor at normal condition.

\begin{tabular}{|c|c|c|c|c|c|c|c|c|c|}
\hline & & step path & & & & & al pat & & \\
\hline $\mathrm{R}^{2}$ & TV & VIF & DV & IV & $R^{2}$ & TV & VIF & DV & IV \\
\hline 0.99 & 0.001 & 980.75 & WSY & $\mathrm{RD}$ & 0.98 & 0.82 & 1.20 & WSY & $\mathrm{RD}$ \\
\hline & 0.017 & 57.71 & & SY & & 0.66 & 1.51 & & SY \\
\hline & 0.01 & 104.78 & & $\mathrm{MC}$ & & 0.72 & 1.37 & & $\mathrm{MC}$ \\
\hline & 0.02 & 48.78 & & SC & & 0.86 & 1.15 & & $\mathrm{SC}$ \\
\hline & 0.03 & 31.63 & & RL & 0.47 & 0.99 & 1.01 & $\mathrm{RD}$ & RL \\
\hline & 0.003 & 314.57 & & RY & 0.94 & 0.72 & 1.37 & SY & RY \\
\hline & 0.001 & 671.83 & & CDW & & 0.86 & 1.16 & & CDW \\
\hline & 0.008 & 127.68 & & WUE & & 0.70 & 1.41 & & WUE \\
\hline & 0.003 & 310.68 & & $\mathrm{Na}$ & & 0.68 & 1.45 & & $\mathrm{Na}$ \\
\hline & 0.004 & 247.31 & & $\mathrm{~K}$ & 0.88 & 0.96 & 1.03 & $\mathrm{MC}$ & $\mathrm{K}$ \\
\hline & 0.01 & 78.17 & & $\mathrm{~N}$ & & 0.61 & 1.62 & & $\mathrm{~N}$ \\
\hline & 0.14 & 7.02 & & RD & & 0.72 & 1.37 & & RY \\
\hline & 0.01 & 54.02 & & WU & & 0.24 & 4.04 & & $\mathrm{Na}$ \\
\hline & 0.006 & 173.23 & & LAI & 0.56 & 0.31 & 3.16 & SC & $\mathrm{Na}$ \\
\hline & 0.02 & 43.92 & & PDW & 0.36 & 0.59 & 1.67 & RL & SLW \\
\hline & & & & & & 0.41 & 2.39 & & WU \\
\hline & & & & & 0.28 & 0.62 & 1.60 & K & WU \\
\hline & & & & & & 0.55 & 1.81 & & ALC \\
\hline & & & & & 0.21 & 0.66 & 1.49 & $\mathrm{~N}$ & ALC \\
\hline & & & & & 0.31 & 0.86 & 1.15 & RY & LAI \\
\hline & & & & & 0.19 & 0.61 & 1.62 & CDW & SLW \\
\hline & & & & & & 0.71 & 1.40 & & LAI \\
\hline & & & & & 0.58 & 0.50 & 1.98 & WUE & PDW \\
\hline & & & & & 0.24 & 0.55 & 1.81 & $\mathrm{Na}$ & PDW \\
\hline
\end{tabular}

A high degree of multicollinearity can be explained by values greater than 10 for VIF (variance inflation factor) and values smaller than 0.1 for TV (tolerance value); DV, dependent variable; IV, independent variable; WSY, white sugar yield; RY, root yield; SY, sugar yield; SC, sugar content; WUE, water use efficiency; WU, water use; MC, molasses content; ALC, alkaline level content; N, -amino-N; Na, sodium; K, potassium; RL, root length; RD, root diameter; LAR, leaf area ratio; LWR, leaf weight ratio; SLW, specific leaf weight; LAI, leaf area index; TDW, total dry weight; CDW, crown dry weight; PDW, petiole dry weight; RDW, root dry weight; LDW, leaf dry weight. 


\section{Discussion}

Although analysis of path coefficients has been around for some time, the reports indicating its use in sugar beet is very limited (Behl and Singh, 1977; Smith et al., 1977; Er et al., 2009). In the latest report a positive correlation $(+0.630)$ was found between rainfall and monthly mean sugar content (Er et al., 2009), emphasizing on the effect of negative effect of drought.

Because of current environmental changes, drought stress has become the major limitation factor on plant yield at global scale (Yordanov et al., 2000). In sugar beet, water shortage greatly affects beet root quality (Pidgeon et al., 2001; Bagatta et al., 2004) and to a less degree affects root yield. Despite the drastic influence of drought on sugar beet shoot, the taproot yield mainly remains less affected since an effective osmotic adjustment mechanism is present (Clarke et al., 1993; Abdollahian-Noghabi and Froud-Williams, 1998; Hsiao, 2000; Shaw et al., 2002). However in an earlier report, a reduction of 16.1$51.6 \%$ in both root yield and sugar yield was noted upon water stress depending on the drought timing during the growth season (Choluj et al., 2004). Meanwhile, water stress causes the accumulation of nonsugar compound impurities (glycine betaine, proline, potassium, sodium, $\alpha$-amino-N) leading to a great reduction of taproot sugar yield (Harvey and Dutton, 1993).

An effective approach towards lessening the effects of drought on sugar beet is selection within cultivated and wild types for tolerant varieties and their use in future crossing programs. Taking these measures would not be successful, unless a comprehensive knowledge of interrelationship among traits would be available. Simple correlation studies might be informative in selection steps, but fails to produce a rather perfect picture about relative importance of each trait. Furthermore, it does not reveal how the other traits affect the target trait, usually yield; is it through direct effects? or considering that we are living at the era of systems biology, does it affect indirectly and via other biological networks or traits? To address these matters, a multivariate statistical analysis such as path analysis may unravel the interrelationships of these traits. In path analysis, the direct and indirect shares of each trait on yield are being revealed according to the relative magnitude of correlation coefficients (Board et al. 1997; Hobbs and Mahon, 1982). Our aim here was to develop selection indices for higher white sugar yield at normal and drought stress condition via both simple correlation analysis and sequential path analysis and further to demonstrate the advantage of this method over single-step path analysis.

Farmers usually withdraw irrigation some time before harvest to increase the sugar yield by taproot dehydration. Though, a balance needs to be established between dehydration and stressing sugar beet plants (Morrilo-Velarde and Ober, 2006). In this study a negative correlation was noticed between water used and both white sugar yield and root yield under normal condition (Table 1), emphasizing on better field management through managing the irrigation at late season.

In both conditions sugar yield had the highest effect on WSY. Consecutively, root yield and sodium content had the major positive and negative effects on SY respectively. This demonstrates that sodium content inhibits the extraction of sugar and lowers both SY and WSY. The remaining traits with minor effects on WSY were molasses content (negative effect) and sugar content (positive effect) in both conditions, except that root diameter appeared only in normal condition.

Higher percentage of coefficient (close to 1.00 ) between a predictor

Table 4. Comparison of multicollinearity in sequential path model and conventional path analysis by tolerance value and variance inflation factor at drought-stressed condition.

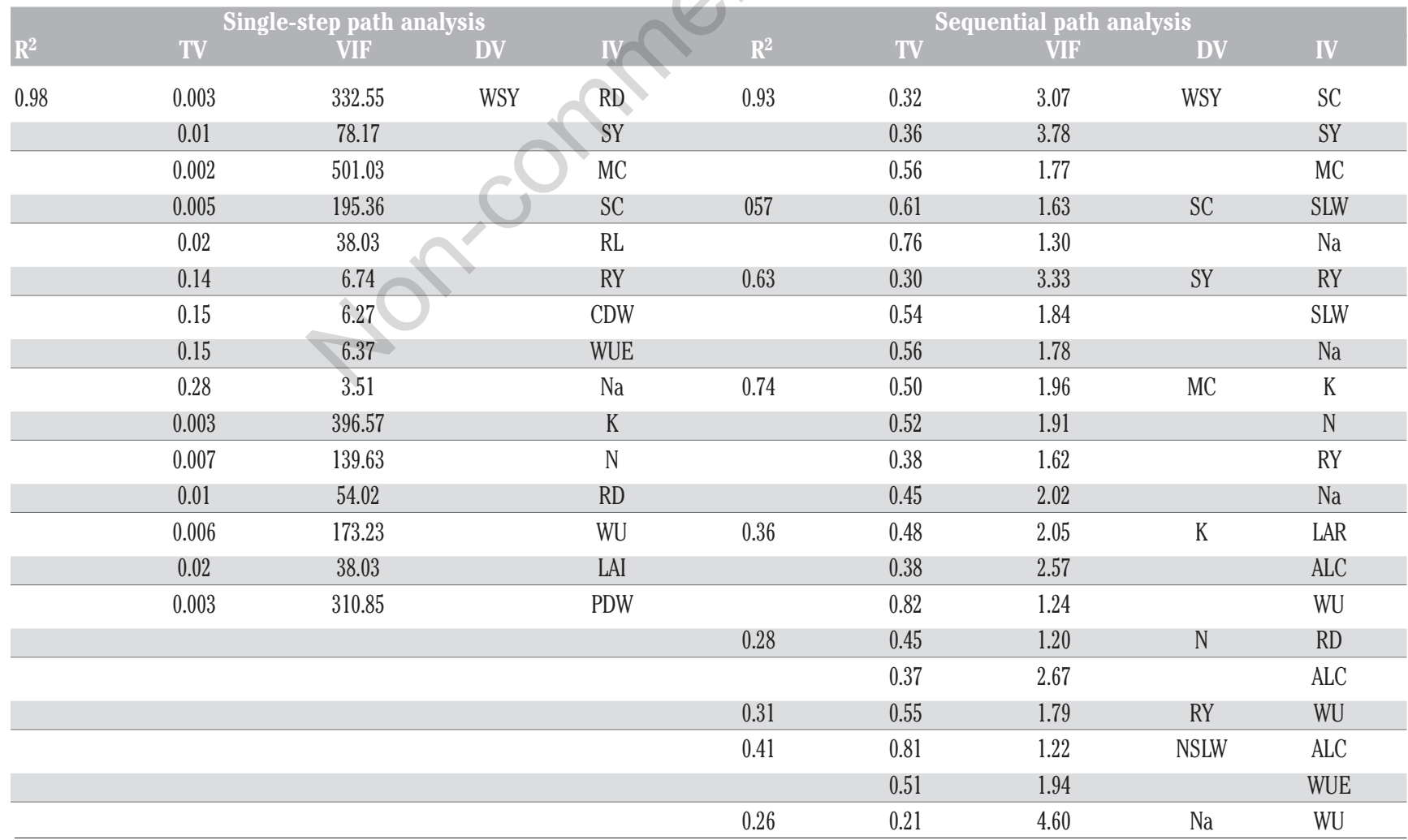

A high degree of multicollinearity can be explained by values greater than 10 for VIF (variance inflation factor) and values smaller than 0.1 for TV (tolerance value); DV, dependent variable; IV, independent variable; WSY, white sugar yield; RY, root yield; SY, sugar yield; SC, sugar content; WUE, water use efficiency; WU, water use; MC, molasses content; ALC, alkaline level content; N, $\alpha$-amino-N; Na, sodium; K, potassium; RL, root length; RD, root diameter; LAR, leaf area ratio; LWR, leaf weight ratio; SLW, specific leaf weight; LAI, leaf area index; TDW, total dry weight; CDW, crown dry weight; PDW, petiole dry weight; RDW, root dry weight; LDW, leaf dry weight. 
variable and the response variable may mask the real effects of other predictor variables. For instance, sugar content appeared only to have a major indirect role on WSY via SY $\left(\mathrm{r}_{\mathrm{WSY}}, \mathrm{SY}=+0.83\right)$ in normal condition. In this case, if the SY is being removed from the model it can be noted that SC will strongly predict the WSY (data not shown). When SC was considered as the dependent trait, sodium content had the major negative effect in both conditions and eventually on WSY. Once molasses content with negative effect on WSY was considered as dependent variable, potassium, sodium and $\alpha$-amino- $\mathrm{N}$, non-sugar impurities, had the positive effect on MC. Nonetheless, in all steps the negative effect of Na on WSY is clear either by lowering sugar yield and content or by improving the molasses content. Furthermore, $\mathrm{K}$ and $\mathrm{N}$ had a major contribution on lowering the WSY via increasing the molasses content.

An important observation was that the specific leaf weight appeared to be meaningful and effective on SY, SC, and WSY in drought-stress condition. This means that selection for sugar beets with leaves that withstand the stress and continue cell expansion and division would be beneficial in breeding programs under stress conditions.

In general, it could be concluded that under normal and droughtstressed conditions the traits that have to be brought under scrutiny during selection procedures are; selection for higher sugar yield and content, and lower non-sugar compounds. Moreover in droughtstressed condition, the plants that withstand better upon water shortage are the varieties with better potential to accumulate more sugars in their taproots. Furthermore we have noticed that similar to previous studies, sequential path analysis provides a more reliable analysis in contrast to single-step path analysis.

\section{References}

Abdollahian-Noghabi M, Froud-Williams RJ, 1998. Effect of moisture stress and re-watering on growth and dry matter partitioning in three cultivars of sugar beet. Asp. Appl. Biol. 52:71-78.

Agrama HAS, 1996. Sequential path analysis of grain yield and its components in maize. Plant Breed 115:343-346.

Asghari-Zakaria R, Fathi M, Hasan-Panah D, 2007. Sequential path analysis of yield components in potato. Potato Res. 49:273-279.

Bagatta M, Bagnaresi P, Arru L, Rognoni S, Perata P, Ranalli P, Mandolino G, 2004. A physiological and molecular description of the water stress in sugar beet. Proc. 48th Meet. Italian Society of Agricultural Genetics, Lecce, Italy.

Behl RK, Singh VP, 1977. Character association, path coefficient and plant type studies in Sugarbeet (Beta vulgaris L.). Indian J. Agr. Res. 11:197-201.

Bhagowati RR, Saikia M, 2003. Character association and path coefficient analysis for yield attributes in open pollinated and hybrid true potato seed populations. Crop Res. 26:286-290.

Birhman RK, Kang GS, 1993. Analysis of variation and interrelationship in potato germplasm. Euphytica 68:17-26.

Board JE, Kang MS, Harville BG, 1997. Path analysis identify indirect selection criteria for yield of late- planted soybean. Crop Sci. 37:879-884.

Chlouj D, Karwwska R, Jasinska M, Haber G, 2004. Growth and dry matter partitioning in sugar beet plants (Beta vulgaris L.) under moderate drought. Plant Soil Environ. 50:265-272.

Clarke NA, Hetschkun H, Jones C, Boswell E, Mar-Faing H, 1993. Identification of stress tolerance trials in sugar beet. In: MB Jackson and ICR Black (eds.) Interacting stresses in plants in changing climate. Springer, Berlin, Germany, pp 511-524.

Dunham R, Clark N, 1992. Croping with stress. Brit. Sugar Beet Rev. 60:10-13.

Er F, Ogut M, Erol AS, 2009. Path analysis and relationships between some climatic parameters and sugar content of sugar beet. Bulg. J. Agric. Sci. 15:222-227.

Gopal J, Gaur PC, Rana MS, 1994. Heritability and intra- and inter- generation associations between tuber yield and its components in potato (Solanum tuberosum L.). Plant Breed 112:80-83.

Gunel E, Oral E, Karadogan T, 1991. Relationships between some agronomic and technologic characters in potatoes. [Article in Turkish]. J. Ataturk Univ. 22:46-53.

GzikA, 1996. Accumulation of proline and pattern of $\alpha$-amino acids in sugar beet plants in response to osmotic, water and salt stress. Environ. Exp. Bot. 36:2938.

Hair JR, Anderson RE, Tatham RL, Black WC, 1995. Multivariate data analysis with readings. Prentice Hall, Englewood Cliffs, NJ, USA.

Hanks RJ, Keller J, Rasmussen VP, Wilson GD, 1976. Line-Source sprinkler for continuous variable irrigation-crop production studies. Soil Sci. Soc. Am. J. 40:426-429.

Hanks RJ, Sisson DV, Hurst RL, Hubbard KG, 1980. Statistical analysis of results from irrigation experiments using the LINE-SOURCE sprinkler system. Soil Sci. Soc. Am. J. 44:886-888.

Harvey CW, Dutton JV, 1993. Root quality and processing. In: DA Cooke and RK Scott (eds.) The sugar beet crop. Chapman \& Hall, New Yor, NY, USA, pp. 517-617.

Hobbs SLA, Mahon JD, 1982. Variation, heritability and relationship to yield of physiological characters in peas. Crop Sci. 22:773-779.

Hsiao TC, 2000. Leaf and root growth in relation to water status. Hort. Sci. 35:1051-1058.

Maity S, Chattarzee BN, 1977. Growth attributes of potato and their inter relationship with yield. Potato Res. 20:337-341.

Milligan SB, Gravois KA, Bischoff KP, Martin FA, 1990. Crop effects on genetics relationships among sugarcane traits. Crop Sci. 30:927-931.

Mohammadi A, Assad MT, 1997. Response of sugar beet varieties to drought stress in different growth periods. [Article in Farsi]. Proc. 4th Iranian Congr. on Agronomy and Plant Breeding, Isfahan University, Isfahan, Iran.

Mohammadi SA, Prasanna BM, Singh NN, 2003. Sequential path model for determining interrelationships among grain yield and related characters in maize. Crop Sci. 43:1690-1697.

Morrilo-Velarde R, Ober ES, 2006. Water use and irrigation. In: AP Draycott (ed.) Sugar beet. Blackwell Publ. Ltd., Oxford, UK, pp. 221-255.

Penman HL, 1970. Woburn irrigation, 1960-1968: Results for rotation crops. J. Agric. Sci. Camb. 75:89-102.

Pidgeon JD, Werker AR, Jaggard KW, Richter GM, Lister DH, Jonse PD, 2001. Climatic impact on the productivity of sugar beet (Beta vulgaris L.) in Europe 1961-1995. Agric. Meteorol. 109:27-37.

Samonte SOPB, Wilson LT, McClung AM, 1998. Path analyses of yield and yieldrelated traits of fifteen diverse rice genotypes. Crop Sci. 38:1130-1136.

Shaw B, Thomas TH, Cooke DT, 2002. Responses of sugar beet (Beta vulgaris L.) to drought and nutrient deficiency stress. Plant Growth Regul. 37:77-83.

Sheikh-Aleslami R, 1997. Laboratorial methods and their application to control food and sugar industries process. Mersa Publ., Tehran, Iran.

Smith GA, Martin SS, Ash KA, 1977. Path coefficient analysis of sugarbeet purity components. Crop Sci. 17:249-253.

Stanek V, Pavlas P, 1934. Z. Zuckerind. Cechoslovak. Rep 59:129-141.

Tuncturk M, ÇiftÇi V, 2005. Selection criteria for potato Breeding. Asian J. Plant Sci. 4: $27-30$

Wang G, Kang MS, Moreno 0, 1999. Genetic analysis of grain-filling rate and duration in maize. Field Crops Res. 61:211-222.

Williams WA, Jones MB, Demment MW, 1990. A concise table for path analysis statistics. Agron. J. 82:1022-1024.

Yildirim MB, Çalikan CF, Çaylak Ö, Budak N, 1997. Multivariate relationships in potatoes. [Article in Turkish]. Proc. 2nd Turkish Field Crops Symp., Samsun, Turkey

Yordanov I, Velikova V, Tsonev T, 2000. Plant responses to drought, acclimation, and stress tolerance. Photosynthetica 38:171-186. 